\title{
ELECTROCOAGULATION TECHNIQUE IN THE TREATMENT OF WASTE WATERS FROM PAPER RECYCLING
}

\author{
Petronela Nechita \\ Department of Environmental, Applied \\ Engineering and Agriculture, Dunărea de Jos \\ University of Galați, Romania
}

\begin{abstract}
Effluents from many industries are one of the major sources of water pollution and represent important environmental problems. Generally, paper recycling process generates large amounts of wastewater. Electrocoagulation (EC) is an evolving technology that has been effectively applied in the treatment of industrial wastewater containing various pollutants, such as textile wastewaters or chemical mechanical polishing wastewaters. This technique has a great ability to remove the pollutants from water due to its high efficiency, economically attractive and relatively lower sludge formation compared with other conventional processes such as biological, physical, chemical, adsorption and advanced oxidation processes. However, electrocoagulation (EC) process has been proposed as alternative to biological, physical and chemical methods due to its environmentally friendly and cheap to operate.

This paper presents the experimental results obtained by applying the electrocoagulation method for removing the organic pollutants (COD) and total suspended solids (TSS) from wastewaters generated in the paper mill that use as raw materials recycled papers.
\end{abstract}

KEYWORDS: electrocoagulation, wastewaters, recycled papers, pollutants, electrochemical cell

\section{Introduction}

The effluents from many industries are one of the major sources of water pollution which represent important environmental problems [1].

The pollutants in water cause considerable damage to the aquatic environment and significant source of environmental pollution. It contains several harmful chemicals that are toxic to biological life. [2].

Generally, paper recycling process generates large amounts of wastewater. Often, these effluents are organic compounds in colloidal or dissolving state containing high amounts of toxic chemicals originate from raw materials, such as resin acids and tannins or are produced during the manufacturing processes (defibration, deinking and bleaching of recycled paper). The most of these pollutants are resistant to biodegradation, having the bioaccumulation ability on the aquatic trophic chain causing long term toxic effects on aquatic organism's life [3].

Reducing water consumption by increasing internal water recirculation after the implementation of internal cleaning processes saves money and also decreases the use of scarce environmental resources. The increasing of wastewaters use has become an absolute necessity and an urgent need to develop inexpensive techniques for treatment of wastewater. Over the past 20 years this industry has reduced water consumption by nearly a half and over the past 30 years by an impressive 95\% per tons of paper. Since the main unit operations associated with papermaking are carried out in aqueous media, the application of various chemical additives can considerably alter the properties of the produced effluents, making it harmful for the receiving environments. However, the total closure of the water circuits is limited by the accumulation of 
contaminants in the water process, which can give rise to corrosion, deposits, and odors and alter both the runnability for the paper machine and the final product quality. If further closure is required, the effluent must be extensively treated so that it can be used again in the papermaking process $[4,5]$.

To overcome this problem a number of conventional treatment techniques have been applied such as catalytic oxidation, adsorption processes, ion exchange, biological processes, membrane separation processes, advanced oxidation processes, ultrafiltration, chemical precipitation, reverse osmosis, photocatalysis, chemical coagulation and electrocoagulation Most of these methods are effective, although they are quite expensive and have many disadvantages and limitations $[6,7,8]$.

Electrocoagulation (EC) is a promising technique for removal of pollutants from wastewater due to its simple, cheap to operate, easily available equipment and environmental friendly [9]. Electrocoagulation (EC) is an evolving technology that has been effectively applied in the treatment of industrial wastewater containing various pollutants, such as textile wastewaters or chemical mechanical polishing wastewaters. In the last years this method has been widely used for the treatment of wastewaters with a different pollutants: heavy metals, oil wastes, dyes, fluorine, refractory organic pollutants including lignin, suspended particles, nitrates, phenols, arsenic, poultry manure wastewater pollutants, having the capability to overcome the disadvantages of the other treatment techniques [10].

Furthermore, this technique has a great ability to remove pollutants from water due to its high decolourization efficiency, economically attractive and relatively low sludge formation compared with other conventional processes such as biological, physical, chemical, adsorption and advanced oxidation processes. However, electrocoagulation (EC) process has been proposed as alternative to biological, physical and chemical methods due to its environmental friendly and cheap to operate [11].

The EC cell consists of electrodes (anode and cathode) and power source. Anodes can be from iron or aluminum, whereas the cathode material can also be inert, such as titanium. When sufficient external current flows in the cell, the iron or aluminum anodes dissolve producing ionic species which have coagulation effect and are further hydrolyzed. At the cathode is produced and released the hydrogen that contributes to separation of colloidal pollutants by flotation. (figure 1)

By EC method are removed the impurities that are in colloidal form, as in chemical coagulation, and the main mechanisms of particle removal are the same for electrocoagulation and inorganic chemical coagulants: double layer compression, adsorption destabilization, agregation and precipitation.

Fig. 1 The mechanism of electrocoagulation process

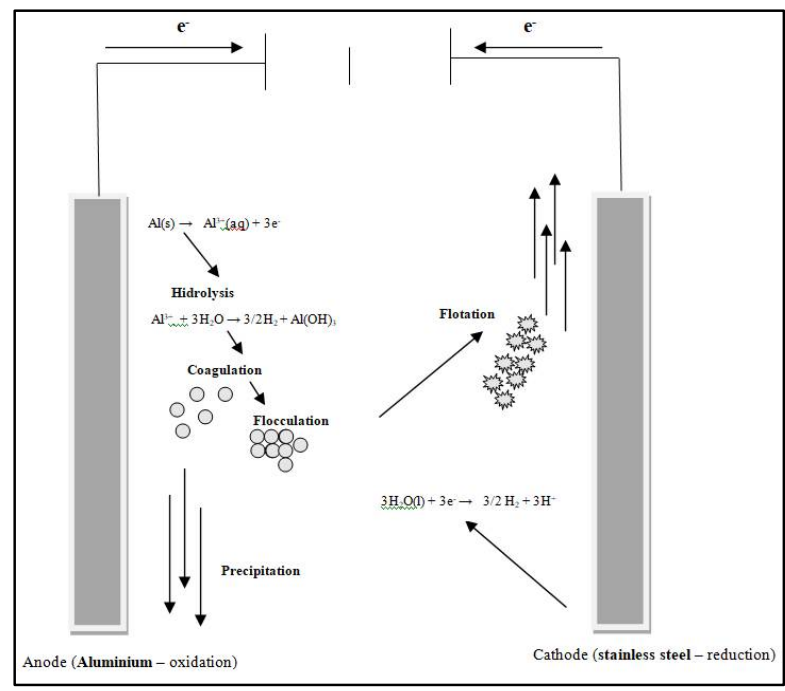

However, there are significant differences between chemical coagulation and electrocoagulation, such as: no anions, such as sulfate or chloride, are added together with metal cations and hydroxides during electrocoagulation; hydrogen produced at the cathode induces flotation that can separate agglomerated particles from water and water $\mathrm{pH}$ increases during electrocoagulation, whereas typical iron and aluminum coagulants decrease water $\mathrm{pH}$ [12].

The electrocoagulation combined with separation technologies such as filtration, sedimentation or flotation offers a potential method for the removal of toxic pollutants from pulp and paper mill wastewaters.

In this context, the paper presents the experimental results obtained by applying an electrocoagulation method for removing of organic pollutants (COD) and total suspended and dissolved solids (TSS, TDS) from wastewaters generated in the paper mill that use as raw materials recycled papers.

\section{Experimental}

\section{Materials and methods}

The electrocoagulation cell which consists in: plastic basin for wastewater (16 L volume), 2 aluminum electrodes (anodes which are dissolved under electrical field and wastewater contact), 2 stainless steel electrodes (cathodes) and electrical power source (24V) (Figure 2). 


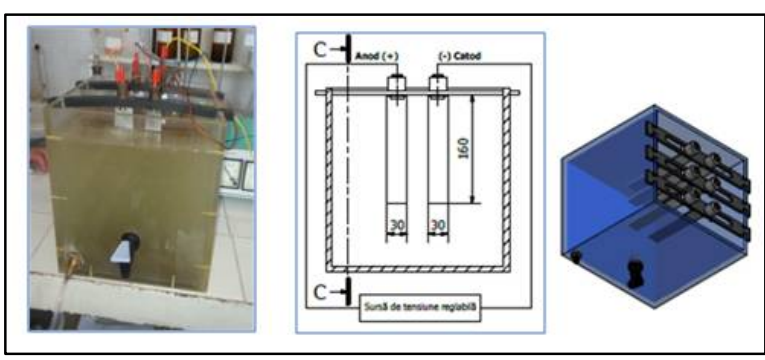

Fig.2 Electrocoagulation cell

The wastewater was collected from wastewater treatment plant of paper recycling processing, before the treatment process.

The technical parameters of the electrocoagulation process are presented in the table 1. The tests were performed in static mode, using as variable the contact time between electrodes and wastewater under the influence of the electric field $(10,15,20$ and 45 min. respectively). In order to evaluate the efficiency of the treatment method, after each set reaction time, samples of purified water were analyzed regarding the content of chemical oxygen demand $\left(\mathrm{CCO}_{\mathrm{Cr}}\right)$ and total suspended and dissolved solids (TSS, TDS). When using aluminum soluble anodes, the electrochemical dissolution occurs with the release in solution of their ions $\left(\mathrm{Al}^{3+}\right)$. By hydrolysis these ions form insoluble hydroxides which have a high adsorption activity against the colloidal and suspended particles.

Table 1 The technical parameters of electrocoagulation process

\begin{tabular}{|l|c|c|c|c|}
\hline \multirow{2}{*}{ Parameter } & \multicolumn{4}{|c|}{ Duration of electrocoagulation process } \\
\cline { 2 - 5 } & $10 \mathrm{~min}$. & $15 \mathrm{~mm}$. & $20 \mathrm{~min}$. & $45 \mathrm{~min}$. \\
\hline Electrical power voltage, $\mathrm{V}$ & 18 & 15 & 15 & 15 \\
\hline Electrical power intensity, $\mathrm{A}$ & 0,8 & 0,8 & 0,8 & 0,8 \\
\hline Distance between electrodes, $\mathrm{cm}$ & 2,5 & 2,5 & 2,5 & 2,5 \\
\hline pH of wastewater & 5,98 & 5,95 & 6,04 & 6,04 \\
\hline Temperature of wastewater, ${ }^{\circ} \mathrm{C}$ & 17,4 & 17,4 & 17,9 & 18,0 \\
\hline Weight of aluminium electrodes, g & 77,4336 & 77,4759 & - & 77,5323 \\
\hline
\end{tabular}

The overall process of oxidation and reduction leads to the formation of hydroxyl species that act as coagulant for suspensions of pollutants from wastewater (Figure 3).

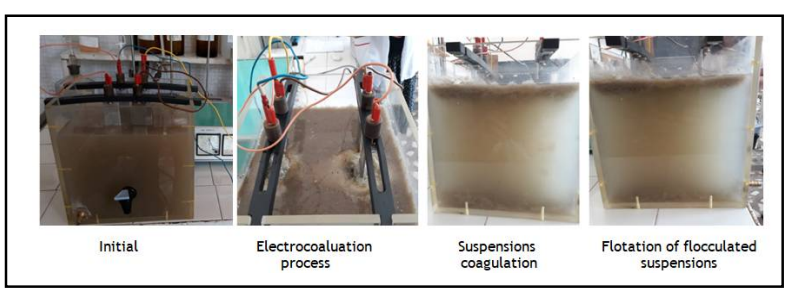

Fig.3 Practical electrocoagulation processes

\section{Results and discussions}

Analyzing the results presented in the figures 4 and 5 it can be observed a reduction of COD and TSS as the electro-coagulation duration is increased. However, the low efficiency (about $13.3 \%$ for TSS and $11.41 \%$ for COD) of the electrocoagulation process is due to the low voltage of electrical power that was during the tests (0.8A) comparing with recommended values of about $3-4 \mathrm{~A}$ as well as the high content of impurities from wastewater (the tests were performed on the wastewater at entrance in wastewater treatment plant).

The efficiency of pollutant removal was calculated using formula:

where:

$$
\varepsilon=\frac{\mathrm{Ci}-\mathrm{Cf}}{\mathrm{Ci}} \times 100, \%
$$

$\mathrm{Ci}$ - pollutant content before treatment, $[\mathrm{mg} / \mathrm{l}]$ $\mathrm{Cf}$ - pollutant content after treatment, [mg/l]

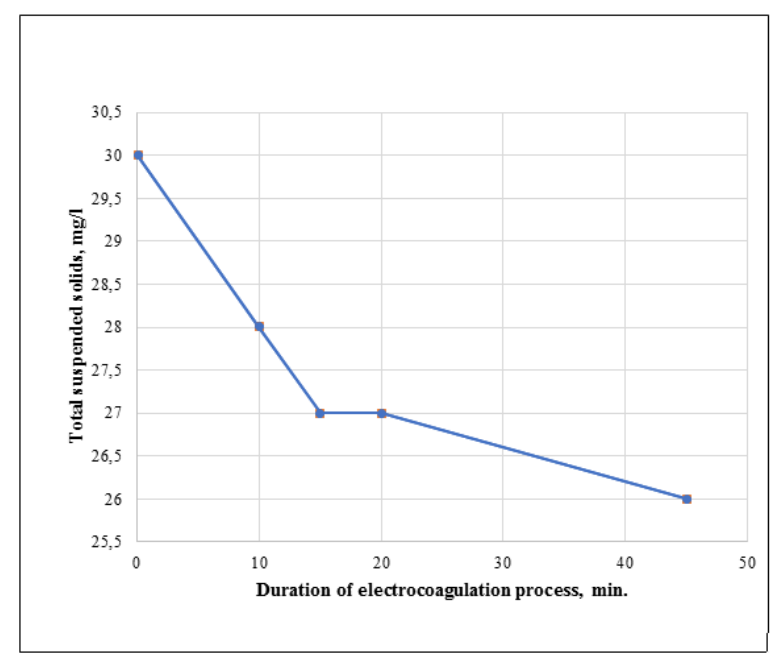

Fig.4 Efficiency of electrocoagulation on TSS removal

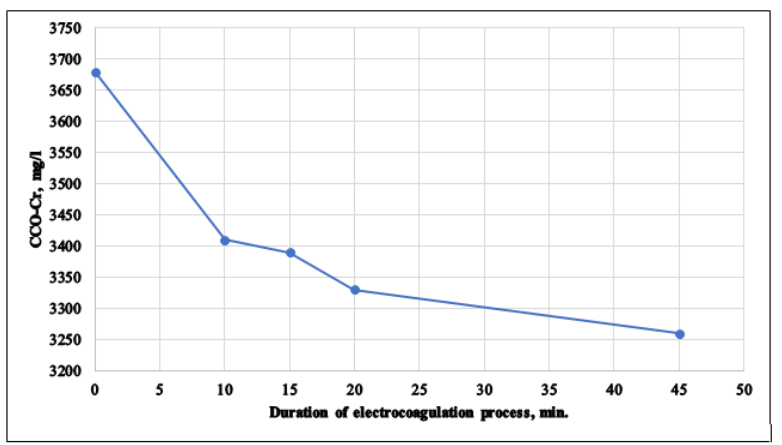

Fig.5 Efficiency of electrocoagulation on COD removal

Increasing of electrocoagulation duration over $15 \mathrm{~min}$. has as effect increasing of total dissolved salts without improving of the pollutants removing (Figure 6). 


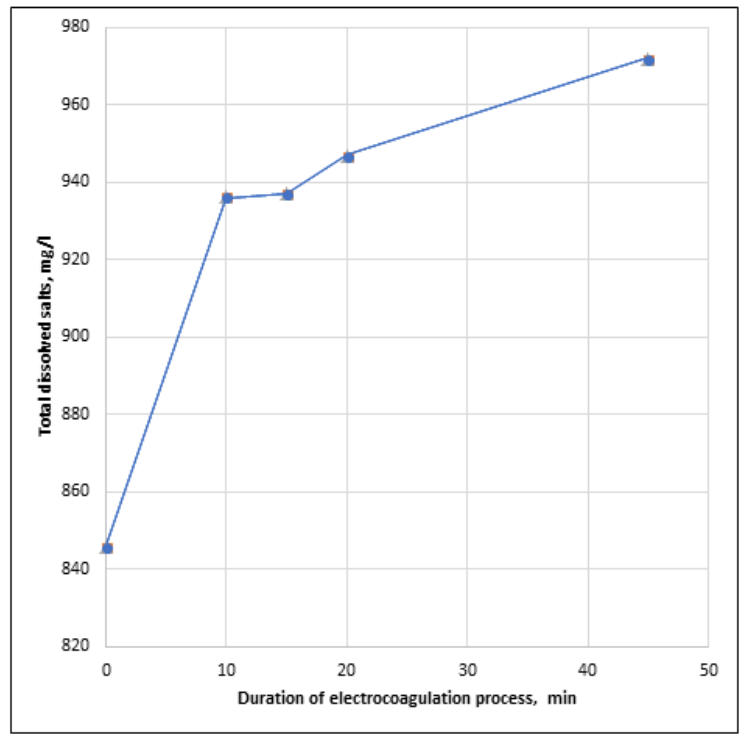

Fig.6The influence of electrocoagulation process on total dissolved solids removal

The study of dissolving process of the aluminum electrodes was realized according the Faraday law. The weight of dissolved metal was calculated using the formula (2).

Where,

$$
m=\frac{\text { MhIt }}{\mathrm{F}},\lceil g\rceil
$$

$\mathrm{m}$ - weight of disolved metal, $\mathrm{g}$

$\mathrm{M}$ - atomic mass of metal, $\mathrm{g}\left(\mathrm{M}_{\mathrm{Al}}=13\right)$

I - intensity of electrical power, A

$\mathrm{t}$ - duration of electrocoagulation process, $\mathrm{s}$

$\mathrm{n}$ - valence of metal

$\mathrm{F}$-Faraday number, $\mathrm{F}=96500$

Based on obtained results, it is emphasized that the dissolving of $1 \mathrm{~g}$ of $\mathrm{Al}$ in water is equivalent with introduction of $6.35 \mathrm{~g}$ of $\mathrm{Al}_{2}\left(\mathrm{SO}_{4}\right)_{3}$ pure, while the dissolving of $1 \mathrm{~g}$ of $\mathrm{Fe}$ is equivalent with introduction in water of $2.93 \mathrm{~g}$ of $\mathrm{FeCl}_{3}$ (Figure 6).

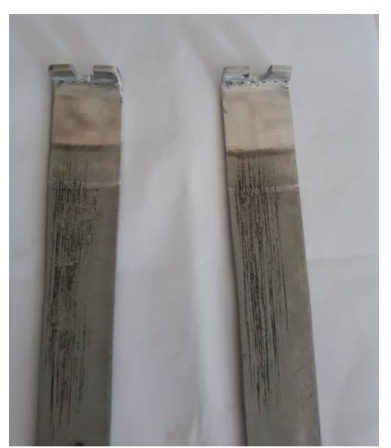

Fig.6 Aluminium electrodes after $45 \mathrm{~min}$. of electrocoagulation process

\section{Conclusions}

The electrocoagulation method can be an effective alternative for industrial wastewater treatment, replacing the use of high cost synthetic coagulants and activated carbon in the stage of physical-chemical treatment.

The main advantage of these processes is their compatibility with the environment, due the fact that the main reagent that is used is the electron which is a "clean" and non-toxic reagent.

\section{References}

[1] Chakchouk I., Elloumi N., Belaid C., Mseddi S., chaari I., Kattel M. (2017), A combined electrocoagulation-electrooxidation treatment for dairy wastewater; Brazilian Journal of Chemical Engineering, 34(1), pp 109-117

[2] Salman Hussein,A., Wail Hassan, A.,(2018) Electrocoagulation Technique Used To Treat Wastewater, American Journal of Engineering Research (AJER) eISSN: 2320-0847 p-ISSN : 2320-0936 Volume-7, Issue$10, \mathrm{pp}-74-88$

[3] M. Ali, T.R. Sreekrishnan, (2001) Aquatic toxicity from pulp and paper mill effluents: a review, Adv. Environ. Res. 5 175-196.

[4].Hubbe et al (2016) Pulp\&paper effluent, BioResources 11(3), 7953-8091

[5] Blanco, A., Negro, C., Monte, C., Fuente, E., and Tijero, J. (2004). The challenges of sustainable papermaking, Environmental Sci. Technol. 38(21), 414A$420 \mathrm{~A}$

[6] Khosravi R., Hazrati S., Fazlzadeh M. (2015), Decolorization of AR18 dye solution by electrocoagulation: sludge production and electrode loss in different current densities; Desalination and Water Treatment, doi: 10.1080/ 19443994. 2015. 1063092, pp 1-9 [7] Sharma S., Can O. T., Hammed M., Nawarathna D., Simsek H. (2018), Organic pollutant removal from edible oil process wastewater using electrocoagulation; IOP Conf. series; series Earth and Environmental Science, doi: 10.1088/17551315/142/1/012079, 142(2018) 012079, pp 1-13

[8] Alizadeh M., Ghahremant E., Sadeghi S. (2015), Removal of reactive green 19 dye from synthetic wastewater using electrocoagulation and aluminum electrodes; Journal of Advances in Environmental Health Research, 3(1), pp 42-48

[9] Vidal J., Espinoza C., Contreras N., Salzar R. (2017), Elimination of industrial textile dye by electrocoagulation using iron electrodes, Journal of chil. Chem. Soc., 62(2), pp 3519-3524

[10] Satish, I. C., (2013), Electrocoagulation: A Novel Waste Water Treatment Method, International Journal of Modern Engineering Research, Vol.3, Issue.1, pp-93-100 [11]Vepsäläinen, M., Kivisaari, H., Pulliainen, M., Oikari, A., Sillanpää, M., (2011) , Removal of toxic pollutants from pulp mill effluents by electrocoagulation, Separation and Purification Technology 81 141-150, doi:10.1016/j.seppur.2011.07.017

[12] Bratby,J.,(2006) Coagulation and Flocculation in Water and Wastewater Treatment, second ed., IWA publishing, London 